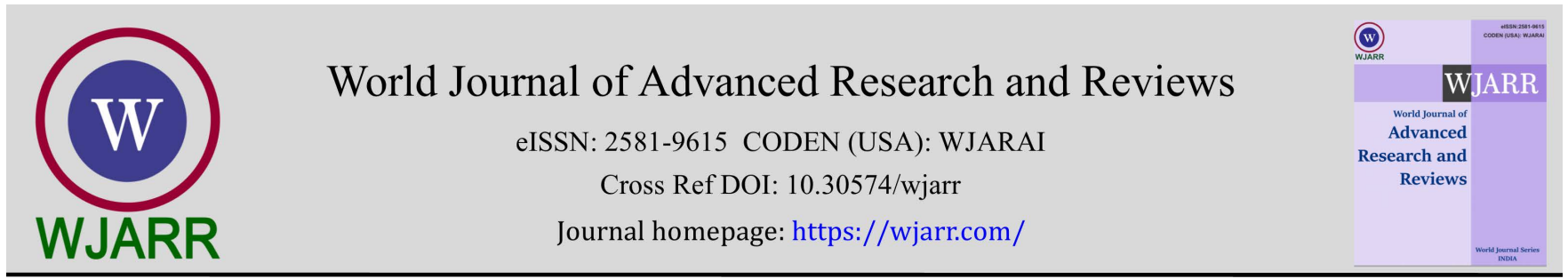

(RESEARCH ARTiClE)

\title{
Prevalence of COVID-19 amongst returning Students of University of Port Harcourt, Port Harcourt, Rivers State, Nigeria
}

\author{
Henrrietta Ogadimma Asuzu-Samuel *, Amanda Adanma Samuel, Sonia Oghenefejiri Jemifor, Osuo-Owene \\ Karibo and Clinton Ubulom Awajigbanam
}
Biomedical Technology Option, School of Science Laboratory Technology, University of Port Harcourt, Choba, Rivers State, Nigeria.

World Journal of Advanced Research and Reviews, 2021, 11(03), 213-219

Publication history: Received on 12 August 2021; revised on 16 September 2021; accepted on 18 September 2021

Article DOI: https://doi.org/10.30574/wjarr.2021.11.3.0446

\begin{abstract}
The causative agent of a mysterious pneumonia was identified as clustered of unexplained pneumonia, was identified as a novel coronavirus in Wuhan, China and was named coronavirus disease 2019 (COVID-19) by the World Health Organization. There are thousands of infectious individuals worldwide and millions of deaths. A total number of 248 subjects (124 males and 124 females) of returning students of some Faculties of University of Port Harcourt were used. Questionnaire were used to collect some demographic data from the subjects while Standard Q COVID-19 Antigen Test Kit methods were applied for the screening. The subjects that gave consent were made to sit down comfortably with their head tilted back and nasal samples collected with COVID-19 swab stick. The swab was inserted into an extraction buffer tube and squeezed at the sides to extract the liquid. 4 drops of the extracted specimen were applied to the well of the Standard Q COVID-19 Antigen Test Kit. The result was read in 20 minutes and was recorded. All the results of the study read negative. This showed zero prevalence of COVID-19 disease amongst the returning students of University of Port Harcourt. This could be as a result of age, environmental factor or strong COVID-19 preventive measures within the campus. Nevertheless, continuous observance of COVID-19 preventive protocols, further COVID-19 screening tests amongst the staff and in a hospital, setting is strongly recommended.
\end{abstract}

Keywords: Coronavirus; COVID-19; Antigen; Prevalence; University Port Harcourt

\section{Introduction}

In late December, 2019 an outbreak of a mysterious pneumonia happened in a seafood wholesale wet market, the Huanan Seafood wholesale Market, in Wuhan, China [1] which involved about $66 \%$ of the staff. However, in January thousands of people in China, including many Provinces were attacked by the rampant spreading of the disease [2]. This disease travelled to other countries such as Japan, Vietnam, Germany, United States, Republic of Korea, and Nigeria. A total of 28,276 confirmed cases with 565 deaths globally were documented by World Health Organization (WHO), involving at least 25 countries in February, 2020 [2]. The pathogen of the outbreak was later identified as a novel betacoronavirus, named 2019 novel coronavirus (2019-nCoV) and this brought back the memory of the severe acute respiratory syndrome (SARS-2003, caused by another beta-coronavirus) that occurred 17 years ago. Symptoms usually include fever, dry cough, fatigue, shortness of breath, sore throat, chest pain, diarrhoea, nausea, vomiting, muscle ache, headache or confusion, loss of taste and smell, a rash on skin or discoloration of fingers or toes [1]. The SARS-CoV-2 virus is thought to spread from person-to-person via: droplets transmission (respiratory droplets from sneeze, cough or drip), aerosol transmission (from coughs or sneezes in the room, aerosolized droplets from talking and singing),

\footnotetext{
* Corresponding author: Henrrietta Ogadimma Asuzu-Samuel

Biomedical Technology Option, School of Science Laboratory Technology, University of Port Harcourt, Choba, Rivers State, Nigeria. 
contact transmission (touching a contaminated surface then touching of mouth, nose or eyes), direct transmission (kissing, shaking hands etc.) [3]

Most cases of COVID-19 are mild. In these cases, the care will include medication such as paracetamol or Non-Steroidal Anti-inflammatory Drugs (NSAIDS) to relieve symptoms (fever, body aches, cough), proper intake of fluids, rest, and nasal breathing [4]. Good personal hygiene and a healthy diet are also recommended [4].

Infection can be prevented by observing personal hygiene practices such as regular washing of hands with soap and running water, alcohol based hand sanitizer, covering cough or sneezing in one's inner flexed arm/elbow or on a tissue paper, staying at home if one has mild symptoms, going to a medical facility if one has more severe symptoms, the use of face masks and making sure one has received all recommended vaccines [5]. The vaccines available are PfizerBioNTech, Johnson and Johnson's Janssen, Moderna [5].

Analyzing samples to assess the current or past presence of SARS-CoV-2 is known as COVID-19 testing. There are two main branches of diagnostic tests which detects the presence of the virus and antibody test which detects antibodies produced in response to infection [5][6]. These tests are also referred to as molecular or genetic assays [7]. Diagnostic tests are divided into reverse transcription polymerase chain reaction test (RT-PCR) and antigen test [8] Antibody tests are divided into rapid diagnostic test, enzyme-linked immunosorbent assay (ELISA), neutralization assay, chemiluminescent immunoassay [9].

A study on the production of COVID-19 PPE's for frontline health workers and the University of Port Harcourt community in response to the COVID-19 pandemic were done [10], with the application of 3D printing technology and various face shield and N-95 nose mask were distributed across the various health facilities in Rivers State, Nigeria and particularly the University of Port Harcourt community to help protect health care workers and patients, reduce the spread of the virus and save lives [10]. The University of Port Harcourt resumed its activities in 2021 [11], students came back to school from different locations in Nigeria amidst the second wave of COVID-19. Most students do not believe in the presence of the virus and may not adhere to the guidelines of the Federal Government and Nigeria Center for Disease Control (NCDC). Hence, this research is relevant to carry out a screening test considering the unknown numbers of persons that are asymptomatic within the school environment. This research will provide a clearer knowledge of the burden of COVID-19 in the University environment and in the country at large, this in turn will help inform appropriate response decisions by the school management. The aim of this research is to investigate the prevalence of COVID-19 pandemic amongst returning students of University of Port Harcourt, Choba, Rivers State, Nigeria.

\section{Material and methods}

Ethical approval was first obtained from the Research Ethics Committee of the University of Port Harcourt which was then presented to the designated Faculty authorities and permission was granted before carrying out the study. A total number of two hundred and forty-eight (248) students of four Faculties (School of Science Laboratory (SSLT), Faculty of Engineering, Faculty of Humanities and Faculty of Science), University of Port Harcourt which comprised of males and females who gave their consent were randomly recruited into the study with informed consent letter duly signed by each participant prior to the COVID-19 disease prevalence study. The study was conducted in the School of Science Laboratory Technology laboratory, University of Port Harcourt located in Choba, Port Harcourt in Rivers State, and questionnaires were used to obtain demographic data by interviewing the subjects. The questions were generated according to the objectives of the study, the first section was designed to collect information on the personal data of the subjects while the second section was on their current health status.

Positive and negative Standard Control of COVID-19 Antigen test kit were used as a guide throughout the test period with the following procedures/steps: The subjects were made to sit down comfortably. The subjects head were tilted back slightly. The nasal swab was inserted less than one inch (about $2 \mathrm{~cm}$ ) into nostril and being rotated until resistance was met at the turbinate. The swab was rotated 4 times against the nasal wall. The above steps were repeated in the other nostril using the same swab. The swab was inserted into an extraction buffer tube. While the buffer tube was being squeezed, the swab was stirred more than 5 times. The swab was removed while squeezing the sides of the tube so as to extract the liquid from the swab. The nozzle cap was pressed tightly on the tube. The test device and the desiccant pack in the foil pouch were checked. 4 drops of extracted specimen was applied to the specimen well of the test device. The result was read within 25 minutes (The results were not read after 30 minutes). The results were recorded. 


\section{Results}

Table 1 Study Results of the Antigen Test kit for COVID-19 in 124 Male Sudents

\begin{tabular}{|c|c|c|c|}
\hline Study group & Positive & Negative & Test result \\
\hline $1-10$ & + & - & - \\
\hline $11-20$ & + & - & - \\
\hline $21-30$ & + & - & - \\
\hline $31-40$ & + & - & - \\
\hline $41-50$ & + & - & - \\
\hline $51-60$ & + & - & - \\
\hline $61-70$ & + & - & - \\
\hline $71-80$ & + & - & - \\
\hline $81-90$ & + & - & - \\
\hline $91-100$ & + & - & - \\
\hline $101-110$ & + & - & - \\
\hline $111-124$ & + & - & - \\
\hline
\end{tabular}

Table 2 Study Results of the Antigen Test kit for COVID-19 in 124 Female Students

\begin{tabular}{|c|c|c|c|}
\hline Study group & Positive & Negative & Test result \\
\hline $1-10$ & + & - & - \\
\hline $11-20$ & + & - & - \\
\hline $21-30$ & + & - & - \\
\hline $31-40$ & + & - & - \\
\hline $41-50$ & + & - & - \\
\hline $51-60$ & + & - & - \\
\hline $61-70$ & + & - & - \\
\hline $71-80$ & + & - & - \\
\hline $81-90$ & + & - & - \\
\hline $91-100$ & + & - & - \\
\hline $101-110$ & + & - & - \\
\hline $111-124$ & + & - & - \\
\hline
\end{tabular}

\subsection{Mean age of patients}

In order to obtain the student mean age of (16 - 32) years of age, a frequency distribution table was constructed using a class limit of three (3) 
Table 3 Age Frequency Distribution Table of the Male Subjects

\begin{tabular}{|l|c|c|c|}
\hline $\begin{array}{l}\text { Class Interval of Age } \\
\text { (Years) }\end{array}$ & $\begin{array}{l}\text { Frequency } \\
\text { (F) }\end{array}$ & $\begin{array}{l}\text { Midpoint (X) of Age } \\
\text { Class Interval }\end{array}$ & $\begin{array}{l}\text { FX } \\
\text { Midpoint) }\end{array}$ \\
\hline $16-18$ & $19(15 \%)$ & 17 & 323 \\
\hline $19-21$ & $41(30 \%)$ & 20 & 820 \\
\hline $22-24$ & $42(34 \%)$ & 23 & 966 \\
\hline $25-27$ & $12(10 \%)$ & 26 & 312 \\
\hline $28-30$ & $4(3 \%)$ & 29 & 116 \\
\hline $31-34$ & $6(5 \%)$ & 32 & 192 \\
\hline & 124 & & 2729 \\
\hline
\end{tabular}

Arithmetic Mean (A.M) is given by the formula below:

$$
\text { A.M }=\frac{\Sigma f x}{f}
$$

Since $\Sigma f x=2729$

$$
\text { A.M }=\frac{2729}{124}
$$

$\therefore \mathrm{A} \cdot \mathrm{M}=22$

Therefore, the mean age of the male students involved in the research is 22 years.

Table 4 Age Frequency Distribution Table of the Female Subjects

\begin{tabular}{|l|c|c|c|}
\hline $\begin{array}{c}\text { Class Interval of Age } \\
\text { (Years) }\end{array}$ & Frequency (F) & $\begin{array}{c}\text { Midpoint (X) of Age } \\
\text { Class Interval }\end{array}$ & $\begin{array}{c}\text { FX (Frequency } \times \\
\text { Midpoint) }\end{array}$ \\
\hline $16-18$ & $36(29 \%)$ & 17 & 612 \\
\hline $19-21$ & $35(28 \%)$ & 20 & 700 \\
\hline $22-24$ & $28(23 \%)$ & 23 & 644 \\
\hline $25-27$ & $23(19 \%)$ & 26 & 598 \\
\hline $28-30$ & $2(2 \%)$ & 29 & 58 \\
\hline & 124 & & 2612 \\
\hline
\end{tabular}

Arithmetic Mean (A.M) is given by the formula below:

$$
\text { A.M }=\frac{\Sigma f x}{f}
$$

Since $\sum f x=2612$

$$
\begin{aligned}
& \text { A.M }=\frac{2612}{124} \\
& \therefore \text { A.M }=21
\end{aligned}
$$

Therefore, the mean age of the male students involved in the research is 21 years. 
Table 5 Temperature Frequency Distribution of all the Subjects

\begin{tabular}{|l|c|c|c|}
\hline $\begin{array}{l}\text { Class interval of } \\
\text { temperature } \mathbf{~}^{\circ} \text { c) }\end{array}$ & $\begin{array}{l}\text { Frequency of } \\
\text { temperature of } \\
\text { subject }\end{array}$ & $\begin{array}{l}\text { Frequency of subjects } \\
\text { with symptoms }\end{array}$ & $\begin{array}{l}\text { Percentage of temperature of } \\
\text { subjects with symptoms }\end{array}$ \\
\hline $35.0-35.4$ & $8(4 \%)$ & 4 & $3 \%$ \\
\hline $35.5-35.9$ & $25(11 \%)$ & 16 & $11 \%$ \\
\hline $36.0-36.4$ & $65(30 \%)$ & 28 & $39 \%$ \\
\hline $36.5-36.9$ & $101(46 \%)$ & 60 & $29 \%$ \\
\hline $37.0-37.4$ & $45(21 \%)$ & 44 & 182 \\
\hline
\end{tabular}

Table 6 Symptoms Observed in all the Subjects

\begin{tabular}{|c|c|c|c|}
\hline Presenting Symptoms & $\begin{array}{l}\text { All Subjects } \\
\qquad(\mathrm{N}=\mathbf{2 4 8})\end{array}$ & $\begin{array}{l}\text { Having Symptoms } \\
\qquad(\mathrm{N}=152)\end{array}$ & $\begin{array}{c}\text { No Symptoms } \\
(\mathrm{N}=96)\end{array}$ \\
\hline Fever & $20(8 \%)$ & $20(13 \%)$ & Nil \\
\hline Cough & $49(20 \%)$ & $48(31 \%)$ & Nil \\
\hline Chills or rigor & $44(18 \%)$ & $44(29 \%)$ & Nil \\
\hline Sore throat & $36(15 \%)$ & $36(24 \%)$ & Nil \\
\hline Shortness of breath & $20(8 \%)$ & $20(13 \%)$ & Nil \\
\hline Runny nose & $44(18 \%)$ & $44(29 \%)$ & Nil \\
\hline Abdominal pain & $40(167 \%)$ & $40(26 \%)$ & $\mathrm{Nil}$ \\
\hline Headache & $101(41 \%)$ & $100(66 \%)$ & Nil \\
\hline Loss of taste or smell & $16(6 \%)$ & $16(11 \%)$ & Nil \\
\hline Confusion & $32(13 \%)$ & $32(21 \%)$ & $\mathrm{Nil}$ \\
\hline Malaise & $12(5 \%)$ & $12(8 \%)$ & Nil \\
\hline Diarrhea & $12(5 \%)$ & $12(8 \%)$ & Nil \\
\hline Nausea & $28(11 \%)$ & $28(18 \%)$ & $\mathrm{Nil}$ \\
\hline Vomiting & $12(5 \%)$ & $12(8 \%)$ & Nil \\
\hline Chest pain & $28(11 \%)$ & $28(18 \%)$ & Nil \\
\hline Fatigue & $56(23 \%)$ & $56(37 \%)$ & Nil \\
\hline Joint pain & $44(18 \%)$ & $44(29 \%)$ & Nil \\
\hline
\end{tabular}

\section{Discussion}

The negative results obtained from the 248 subjects tested in the study as stated in the result table are close to the results obtained [12]. on "malaria and COVID-19 patients", which stated that COVID-19 patients were usually asymptomatic or had mild symptoms which could be missed by targeted surveillance and testing, and the lower than expected number of cases detected in Africa suggested that the young age structure may have been the reason for low detection cases. 
The results obtained in the study are also in line with the study on "Clinical and epidemiological characteristics of 646 hospitalized SARS-CoV-2 (COVID-19) positive patients in Rivers State, Nigeria" [13], reported that COVID-19 symptoms were more severe in patients aged 50 and above. This explains why this study may have obtained zero prevalence amongst returning students of the University whose age range fell within 16 and 34 for 248 study subjects.

The arithmetic mean age of 22years for males and 21years for females as obtained in this study is close to the median age of 20 years obtained [12] on malaria and COVID-19, in their study showed that subjects with the median age of 20 and lower were usually asymptomatic and could be missed in testing for COVID-19 cases. This also could explain why the lower age as seen in the mean age in this study also tested negative for the COVID-19 with zero prevalence. The temperature range of $37.0-37.4^{\circ} \mathrm{C}$ seen in this study also had symptoms of COVID-19 which is in line with the findings of [12] which reported that the symptoms of COVID-19 are similar to those of malaria. From the questionnaires distributed to the 248 subjects, it was gathered that 152 subjects out of 248 had COVID-19 symptoms despite testing negative as shown in the result table. The symptoms were fever, cough, chills or rigor, sore throat, shortness of breath, runny nose, abdominal pain and headache, loss of taste or smell, confusion, malaise, diarrhea, nausea, vomiting, chest pain, fatigue and joint pain. All the 152 subjects had more than a symptom. Study on malaria and COVID-19 [12] showed symptoms of fever, difficulty in breathing, fatigue and headache in some of the patients but were sent home due to a negative COVID-19 test result. The symptoms would have been as a result of malaria, which might also be related to the result of this study because there are similarities between malaria and COVID-19.

The negative results obtained in this study may be attributed to environmental factor, age, comorbidities and strong COVID-19 preventive measures within the campus Patients in the hospital environment, age 50 and above are significantly more likely to have the disease compared to patients below 50 years [13] and returning students.

\section{Conclusion}

There are various reports on the prevalence of COVID-19 worldwide. A study [12] was done which shed light on how the similarity of malaria and COVID-19 symptoms may misdiagnose a malaria case as COVID-19 or vice versa or may overlook the possible co-infection. Another study on the clinical and epidemiology characteristics of 646 hospital SARSCoV-2 positive patients in Rivers State [13] reported that age of patients with COVID-19 had been documented as a key determinant of the disease, which is in conformity with the results of this study. Therefore, from the results of the study, the prevalence of COVID-19 disease amongst returning students of University of Port Harcourt with mean aged 22 years for the males and 21years for the females is Zero (Zero prevalence), as seen after the Standard Q COVID-19 antigen test kit sample was analyzed.

\section{Compliance with ethical standards}

\section{Acknowledgments}

We wish to acknowledge the Dean, School of Science Laboratory Technology for the laboratory building and enabled environment provided and all the students that participated in this study across the faculties. We also wished to acknowledged the University of Port Harcourt through the Ethics committee of the University, for the ethical approval we received and to all, we say thank you.

\section{Disclosure of conflict of interest}

There is no conflict of interest from the both authors, hence the manuscript be published.

\section{Statement of informed consent}

Informed consent was obtained from all the participants before the study

\section{References}

[1] Huang D, Lian X, Song F, Ma H, Lian Z, Liang , Qin T, Chen W, Wang S. Clinical Features of severe Patients Infected with 2019 Novel Coronavirus; a systemic review and meta-analysis. Ann Transl Med. 2020; 8(9): 576.

[2] World Health Organization (WHO). Coronavirus Disease 2019 (COVID-19) Situation Report. 2020.

[3] Nigeria Centre for Disease Control (NCDC). An Update of COVID-19 Outbreak in Nigeria. 2020. 
[4] Wang Y, Chen Y, Qin Q. Unique Epidemiological and Clinical Features of the Emerging 2019 Novel Coronavirus Pneumonia (COVID-19) Implicate Special Control Measures. Journal of Medical Virology. 2020; 92(6): 568-576.

[5] Centers for Disease Control and Prevention (CDC). Types of vaccines available. 2021.

[6] Kobokovich A, West R, Gronvall G. Global Progress on COVID-19 Serology Based testing. John's Hopkins Center for Health Security. 2020.

[7] Kubina R, Dziedzic A. Molecular and Serological Tests for COVID-19. A Comparative Review of SARS-CoV-2 Coronavirus Laboratory and Point-of-Care Diagnostics. Diagnostics. 2020; 10(6): 434.

[8] Stephen M. Coronavirus (COVID-19) Update: FDA Authorizes First Antigen Test to Help in the Rapid Detection of the Virus that Causes COVID-19 in Patients. FDA Archive. 2020.

[9] West R, Kobokovich A, Connell N, Gronvall GK. COVID-19 Antibody Tests: A Valuable Public Health Tool with Limited Relevance to Individuals. Trends Microbiol. 2021; 29(3): 214-223.

[10] David LK, Ebieto CE, Asuzu-Samuel HO. Production of COVID-19 PPE for Frontline Health Workers and the University of Port Harcourt Community. Journal of Anatomical Science. 2021; 12(1): 181-187.

[11] University of Port Harcourt (UNIPORT) University of Port Harcourt Proposed Academic Calendar for 2019/2020 Academic Session and 2020/2021.

[12] Hussein MIH, Albashir AAD, Elawad OAMA, Homeida A. Malaria and COVID-19: Unmasking their Ties. Mala Journal. 2020; 19: 457.

[13] Alasia D, Owhonda G, Marika O, Nwadiuto I, Arugu G, Tobin-West C, Azi E, Oris-Onyinri V, Urang I, Ability V, Ohofinuka A, Adebiyi O, Somiari A, Avundea H, Aluni A. Clinical and Epidemiological Characteristics of 646 Hospitalized SARS-CoV-2 Positive Patients in Rivers state, Nigeria: a Prospective Observational study. Pan African Medical Journal. 2021; 38(25): 1-16. 